\title{
Cloud optical and microphysical properties derived from ground-based and satellite sensors over a site in the Yangtze Delta region
}

Article

Published Version

Liu, J., Li, Z., Zheng, Y., Chiu, J. C., Zhao, F., Cadeddu, M., Weng, F. and Cribb, M. (2013) Cloud optical and microphysical properties derived from ground-based and satellite sensors over a site in the Yangtze Delta region. Journal of Geophysical Research: Atmospheres, 118 (16). pp. 9141-9152. ISSN 21698996 doi: https://doi.org/10.1002/jgrd.50648 Available at https://centaur.reading.ac.uk/33727/

It is advisable to refer to the publisher's version if you intend to cite from the work. See Guidance on citing.

To link to this article DOI: http://dx.doi.org/10.1002/jgrd.50648

Publisher: American Geophysical Union

All outputs in CentAUR are protected by Intellectual Property Rights law, including copyright law. Copyright and IPR is retained by the creators or other copyright holders. Terms and conditions for use of this material are defined in the End User Agreement. 


\section{www.reading.ac.uk/centaur}

\section{CentAUR}

Central Archive at the University of Reading

Reading's research outputs online 


\title{
Cloud optical and microphysical properties derived from ground-based and satellite sensors over a site in the Yangtze Delta region
}

\author{
Jianjun Liu, ${ }^{1,2,3}$ Zhanqing Li, ${ }^{1,2}$ Youfei Zheng, ${ }^{3}$ J. Christine Chiu, ${ }^{4}$ Fengsheng Zhao, ${ }^{2}$ \\ Maria Cadeddu, ${ }^{5}$ Fuzhong Weng, ${ }^{6}$ and Maureen Cribb $^{2}$ \\ Received 14 February 2013; revised 18 May 2013; accepted 11 July 2013.
}

[1] Comprehensive surface-based retrievals of cloud optical and microphysical properties were made at Taihu, a highly polluted site in the central Yangtze Delta region, during a research campaign from May 2008 to December 2009. Cloud optical depth (COD), effective radius $\left(\mathrm{R}_{\mathrm{e}}\right)$, and liquid water path (LWP) were retrieved from measurements made with a suite of ground-based and spaceborne instruments, including an Analytical Spectral Devices spectroradiometer, a multifilter rotating shadowband radiometer, a multichannel microwave radiometer profiler, and the Moderate Resolution Imaging Spectroradiometer (MODIS) on Terra and Aqua satellites. Retrievals from zenith radiance measurements capture better the temporal variation of cloud properties than do retrievals from hemispherical fluxes. Annual mean LWP, COD, and $\mathrm{R}_{\mathrm{e}}$ are $115.8 \pm 90.8 \mathrm{~g} / \mathrm{m}^{2}, 28.5 \pm 19.2$, and $6.9 \pm 4.2 \mu \mathrm{m}$. Over $90 \%$ of LWP values are less than $250 \mathrm{~g} / \mathrm{m}^{2}$. Most of the COD values (>90\%) fall between 5 and 60 , and $\sim 80 \%$ of $\mathrm{R}_{\mathrm{e}}$ values are less than $10 \mu \mathrm{m}$. Maximum (minimum) values of LWP and $\mathrm{R}_{\mathrm{e}}$ occur in summer (winter); COD is highest in winter and spring. Raining and nonraining clouds have significant differences in LWP, COD, and $R_{\mathrm{e}}$. Rainfall frequency is best correlated with LWP, followed by COD and $\mathrm{R}_{\mathrm{e}}$. Cloud properties retrieved from multiple ground-based instruments are also compared with those from satellite retrievals. On average, relative to surface retrievals, mean differences of satellite retrievals in cloud LWP, COD, and $\mathrm{R}_{\mathrm{e}}$ were $-33.6 \mathrm{~g} / \mathrm{m}^{2}(-26.4 \%),-5.8(-31.4 \%)$, and $2.9 \mu \mathrm{m}(29.3 \%)$ for 11 MODIS-Terra overpasses and $-43.3 \mathrm{~g} / \mathrm{m}^{2}(-22.3 \%),-3.0$ $(-10.0 \%)$, and $-1.3 \mu \mathrm{m}(-12.0 \%)$ for 8 MODIS-Aqua overpasses, respectively. These discrepancies indicate that MODIS cloud products still suffer from large uncertainties in this region.

Citation: Liu, J., Z. Li, Y. Zheng, J. C. Chiu, F. Zhao, M. Cadeddu, F. Weng, and M. Cribb (2013), Cloud optical and microphysical properties derived from ground-based and satellite sensors over a site in the Yangtze Delta region,

J. Geophys. Res. Atmos., 118, doi:10.1002/jgrd.50648.

\section{Introduction}

[2] Clouds play an important role in the Earth's climate [Ramanathan et al., 1989; Hartmann, 1993]. Specification of their macrophysical, microphysical, and optical properties is among the largest uncertainties in estimating the impact of clouds on the radiative field in global circulation models [Houghton et al., 2001; Forster et al., 2007; Turner et al., 2007]. Testing and improving parameterization schemes for cloud processes and aerosol-cloud interactions requires a

\footnotetext{
${ }^{1}$ State Laboratory of Earth Surface Process and Resource Ecology and College of Global Change and Earth System Science, Beijing Normal University, Beijing, China.

Corresponding author: Z. Li, State Laboratory of Earth Surface Process and Resource Ecology and College of Global Change and Earth System Science, Beijing Normal University, Xinjiekouwai Street No.19, Beijing, 100875, China. (zli@atmos.umd.edu)

(C)2013. American Geophysical Union. All Rights Reserved. 2169-897X/13/10.1002/jgrd.50648
}

good knowledge of cloud properties [e.g., Wood et al., 2009; Fan et al., 2012].

[3] Among cloud optical properties, cloud optical depth (COD) is the most fundamental cloud property. So it is essential that global climate models correctly reproduce spatial and temporal variations of COD [Beaulne et al., 2005]. However, it is well known that clouds differ considerably from one region to another and that the representation of clouds in climate models, especially their optical and microphysical properties, is still poor [Zhang et al., 2005; Bender et al.,

\footnotetext{
${ }^{2}$ Department of Atmospheric and Oceanic Science and Earth System Science Interdisciplinary Center, University of Maryland, College Park, Maryland, USA.

${ }^{3}$ Jiangsu Key Laboratory of Atmospheric Environment Monitoring and Pollution Control, Nanjing University of Information Science and Technology, Nanjing, China.

${ }^{4}$ Department of Meteorology, University of Reading, Reading, UK.

${ }^{5}$ Argonne National Laboratory, Lemont, Illinois, USA.

${ }^{6}$ NOAA/Center for Satellite Applications and Research, College Park, Maryland, USA
} 
(a)

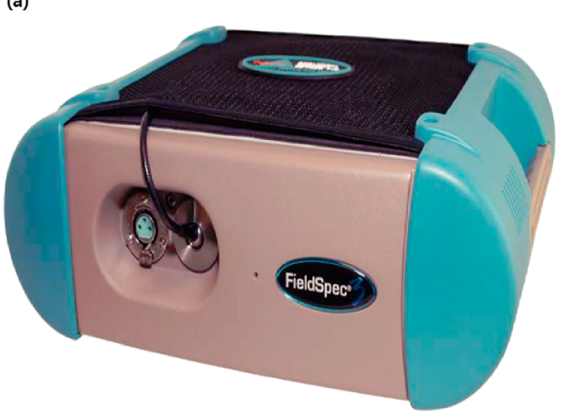

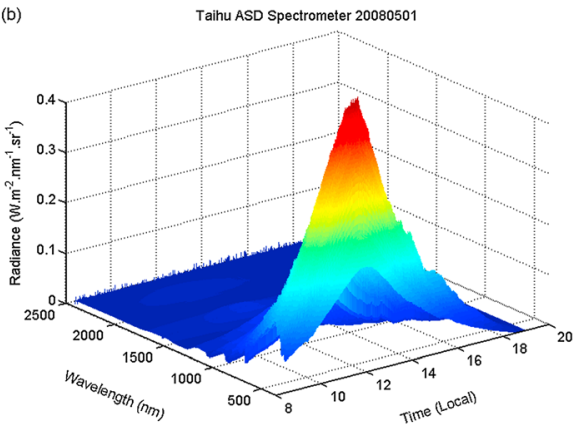

Figure 1. (a) The ASD spectroradiometer used during the campaign and (b) an example of zenith radiance measurements.

2006]. Thus, a dramatic improvement in the knowledge of cloud optical and microphysical properties is needed.

[4] Satellite observations have been employed routinely to retrieve cloud properties on a global scale [Rossow and Garder, 1993; King et al., 2004; Stephens and Kummerow, 2007]. There are many sources of uncertainty and error with satellite-based retrieval methods, such as cloud morphological inhomogeneities and the vertical variation of cloud microphysics [Pincus et al., 2012]. Conventional methods of retrieving droplet effective radius $\left(\mathrm{R}_{\mathrm{e}}\right)$ and liquid water path (LWP) assume a constant $R_{e}$, which can incur significant biases to the retrieval of LWP-based COD and $\mathrm{R}_{\mathrm{e}}$ [Chen et al., 2007]. The problem can be alleviated by using Moderate Resolution Imaging Spectroradiometer (MODIS) multichannel IR radiances [Chang and Li, 2002, 2003].

[5] Independent ground-based estimates of cloud properties are useful for validating satellite-based retrievals and for closure tests when observations from multiple platforms are available [Li et al., 1999]. Up until now, few groundbased cloud measurements have been made in China. Over the heavily populated and quickly developing regions of China, a unique climate issue emerges concerning the impact of human activities. Although initial attempts have been made to address it [Li et al., 2007, 2011], the complex problem of aerosol-cloud interactions remains challenging. Coping with this complex problem requires a good knowledge of both aerosol and cloud properties.

[6] As part of the East Asian Studies of Tropospheric Aerosols and their Impact on Regional Climate (EASTAIRC) campaign that was carried out from May 2008 to December 2009 [ $L i$ et al., 2011], several state-of-the-art instruments were operated at a site in the center of the Yangtze Delta region. Comprehensive measurements are highly valuable and unique for pursuing numerous studies concerning, among others, validation of satellite cloud retrievals, as is attempted here; testing cloud parameterization schemes; and understanding aerosol-cloud-precipitation interactions [e.g., Fan et al., 2012] under heavy aerosol loading conditions in a moist environment.

[7] This paper is concerned with the retrieval of cloud optical and microphysical properties from surface measurements and comparisons with MODIS satellite retrievals. Seasonal variations and differences between raining and nonraining clouds are also examined. A brief description of the measurements and the methodology are given in section 2. Comparisons between COD retrieved from the Analytical Spectral Devices (ASD) spectroradiometer and from the multifilter rotating shadowband radiometer (MFRSR) under cloudy-sky conditions are shown in section 3. Surface and satellite-based retrievals of COD, LWP, and $\mathrm{R}_{\mathrm{e}}$ are compared. Their statistical characteristics and differences between raining and nonraining clouds are also presented in this section. A summary is given in section 4 .

\section{Measurements and Methodology}

[8] To fulfill the scientific objectives of the EAST-AIRC [Li et al., 2011], extensive measurements were made to characterize atmospheric, aerosol, cloud, and surface conditions. The instrumentation was deployed at the Taihu station, located about $100 \mathrm{~km}$ west of Shanghai $\left(31.702^{\circ} \mathrm{N}\right.$, $120.358^{\circ} \mathrm{E}, 10 \mathrm{~m}$ above sea level). Cloud parameters were measured using, among others, a microwave radiometer profiler (MWRP) by Radiometrics Corp., a high-resolution spectrometer by ASD, and a MFRSR by Yankee Environmental Systems. From these measurements, we can obtain COD [Min and Harrison, 1996; Marshak et al., 2004; Chiu et al., 2006], LWP [Liljegren and Lesht, 2004], and $\mathrm{R}_{\mathrm{e}}$ [McComiskey et al., 2009].

\subsection{Instruments and Calibration}

\subsubsection{ASD Spectroradiometer}

[9] The high temporal and spectral resolution ASD spectroradiometer used for the present work is the FieldSpec 3 spectroradiometer, which is a general-purpose spectrometer useful in the measurement of reflectance, transmittance, radiance, and irradiance (http://www.asdi.com/). It is a compact, field-portable precision instrument with a spectral range of $350-2500 \mathrm{~nm}$. A rapid data collection time of $0.1 \mathrm{~s}$ per spectrum (10 spectra per second data collection for the entire $350-2500 \mathrm{~nm}$ range) allows for the screening of all or most samples instead of spot checking. The spectral resolution is $3 \mathrm{~nm}$ (full width at half maximum) at $700 \mathrm{~nm}$, and $10 \mathrm{~nm}$ at 1400 and $2100 \mathrm{~nm}$, and the sampling interval is $1.4 \mathrm{~nm}$ for the spectral region of 350-1000 nm, and $2 \mathrm{~nm}$ for the spectral region of $1000-2500 \mathrm{~nm}$. In our study, 1 min averaged sampling is used to decrease the measurement uncertainty. During the EAST-AIRC campaign, one fore-optics accessory with a $1^{\circ}$ field of view (FOV) was used to measure zenith radiances. A photograph of the instrument and an example of zenith radiance measurements are shown in Figure 1. To our knowledge, no attempt has been made to employ the ASD spectroradiometer for the remote sensing of clouds. 


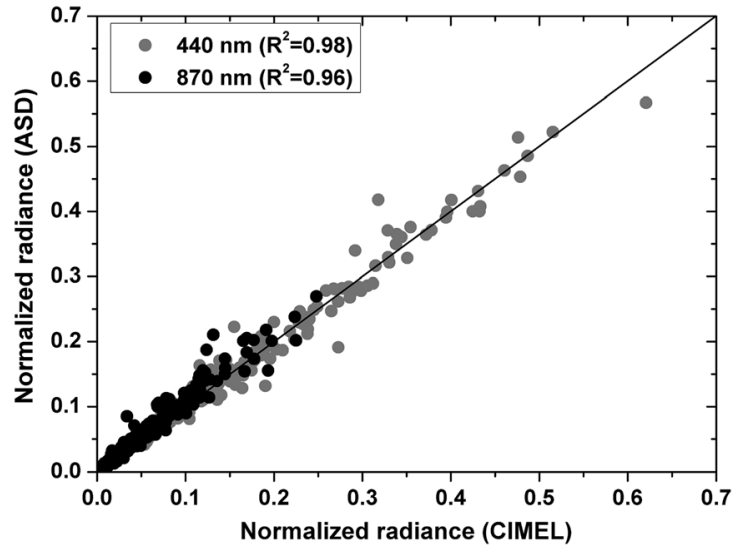

Figure 2. ASD spectroradiometer radiance measurements as a function of CIMEL Sun photometer radiance measurements at 440 and $870 \mathrm{~nm}$.

[10] Prior to the field deployment, the ASD spectroradiometer was calibrated at the NASA Calibration Facility Laboratory. The spectrometer was calibrated with an integrating sphere at four different output energy levels. After calibration, ASD spectroradiometer nominal wavelengths were corrected using the following equations:

$$
\begin{aligned}
y_{1}= & 1.002470 x_{1}-2.166323 \text { for } 350 \sim 1000 \mathrm{~nm} \\
y 1= & 0.999989 x_{1}-1.743782 \text { for } 1001 \sim 1830 \mathrm{~nm} \\
y 1= & 0.0000298208 x_{1}{ }^{2}+0.8644038235 x_{1} \\
& +148.2221616661 \text { for } 1831-2500 \mathrm{~nm},
\end{aligned}
$$

where $x_{1}$ is the ASD spectroradiometer wavelength $(\mathrm{nm})$ and $y_{1}$ is the corrected wavelength (nm). After calibrating the ASD spectroradiometer wavelength, slight changes were made in the radiance as follows:

$$
\begin{aligned}
& y_{2}=1.014798 x_{2}+0.000044 \text { for } 440 \mathrm{~nm} \\
& y_{2}=1.056358 x_{2}-0.001687 \text { for } 870 \mathrm{~nm},
\end{aligned}
$$

where $x_{2}$ is the ASD spectroradiometer-measured radiance and $y_{2}$ is the corrected radiance. Only calibration functions for 440 and $870 \mathrm{~nm}$ are shown here because the retrieval uses radiance measurements made at these wavelengths.

[11] Biases in ASD spectroradiometer radiance measurements were quantified through comparisons with those made by a Cimel Sun photometer from the Aerosol Robotic Network (AERONET), which has been routinely calibrated with high accuracy [Holben et al., 1998]. Such a Sun photometer was installed at Taihu in the fall of 2005 and is still in operation. The instrument has a $1.2^{\circ} \mathrm{FOV}$ and takes measurements at $440,670,870$, and $1020 \mathrm{~nm}$. In addition to direct solar irradiance measurements, the instrument measures the sky radiance along the solar principal plane up to nine times a day and along the solar almucantar up to six times a day; the former measurements contain zenith radiance information. Comparisons of radiance measurements made by the ASD spectroradiometer and Cimel Sun photometer at 440 and $870 \mathrm{~nm}$ are shown in Figure 2. The two sets of measurements agree very well with $\mathrm{R}^{2}=0.98$ $(440 \mathrm{~nm})$ and $\mathrm{R}^{2}=0.96(870 \mathrm{~nm})$.

\subsubsection{The MWRP}

[12] The TP/WVP-3000 MWRP is manufactured by the Radiometrics Corporation [Ware et al., 2003]. It measures atmospheric brightness temperatures at 12 frequencies in the microwave spectrum: five frequencies in the K-band region $(22-30 \mathrm{GHz})$ near a water vapor line, which provide information about LWP and humidity profiles, and seven frequencies between 51 and $59 \mathrm{GHz}$ that provide information about the temperature profile [Gaffard et al., 2008]. A zenithpointing infrared thermometer is used to obtain cloud base and surface temperatures; humidity and pressure at $\sim 1 \mathrm{~m}$ above the surface are also measured. A stream of high-speed air from a dew blower keeps the radiometer's window clear of standing water or snow in case of light precipitation or dew formation. Rain contamination is identified in the data by a flag that is activated when the rain sensor mounted on the radiometer detects water drops. The instrument points in the zenith direction and has a temporal resolution of $\sim 12 \mathrm{~s}$. The instrument FOV varies from $2^{\circ}-3^{\circ}$ beam width in the V-band channel $(50-60 \mathrm{GHz})$ to $5^{\circ}-6^{\circ}$ in the K-band channel $(20-30 \mathrm{GHz})$.

[13] Most of the profiling radiometer parameters that require calibration remain stable for many years [Profiler Operator's Manual, 2006]. These parameters are calibrated at the factory, over the full operating temperature range, and normally require no user adjustment. The adequacy and stability of the factory-calibrated parameters were examined during the data postprocessing and found to be acceptable. The effective noise diode temperature is also very stable, but regular calibration is recommended, especially after transport of the instrument to ensure the best accuracy. The radiometer was continuously calibrated during the deployment using the "TIP-derived calibration" method which is widely described in the literature, where in the radiometer antenna is tipped to several angles to calibrate the radiometer gain standards, for the K-band channels [Han and Westwater, 2000; Cimini et al., 2005] and liquid nitrogen for the V-band channels. The profiling radiometer uses the atmosphere itself as a "cold target" in the TIP method. The calibration is determined by observing the brightness temperature of the sky at several elevation angles in rapid succession, by collecting a large number of tip curves, and by evaluating a median value of the estimated effective noise diode temperature. The median value is then used to calibrate the radiometer gain and system temperature using the technique described in Cadeddu et al. [2013]. Any drift in the instrument gain is accounted for by frequent observations of a black body target. For measurements presented in this paper, the uncertainty in the calibrated brightness temperature was assessed to be $0.5 \mathrm{~K}$ for the K-band channels.

\subsubsection{The MFRSR}

[14] The MFRSR is a seven-channel pyranometer with a hemispheric FOV and a rotating shadow band to block the direct solar beam. It can thus measure total, direct, and diffuse transmittances in narrow bands centered at 415 , $500,610,673,870$, and $940 \mathrm{~nm}$ every $20 \mathrm{~s}$ [Harrison and Michalsky, 1994]. Transmittance of direct radiation can be employed for calibration following the Langley regression method [Min et al., 2004]. Strictly speaking, this method is only valid under the stringent condition of a clear stable atmosphere during the entire daytime, which can hardly be met. This constraint is relaxed by a new method proposed by Lee et al. [2010] that only requires a handful of such cases over a long period of time. Following this method, direct normal irradiance at the top of the atmosphere was determined and the calibration values are then applied to both components of irradiance. 

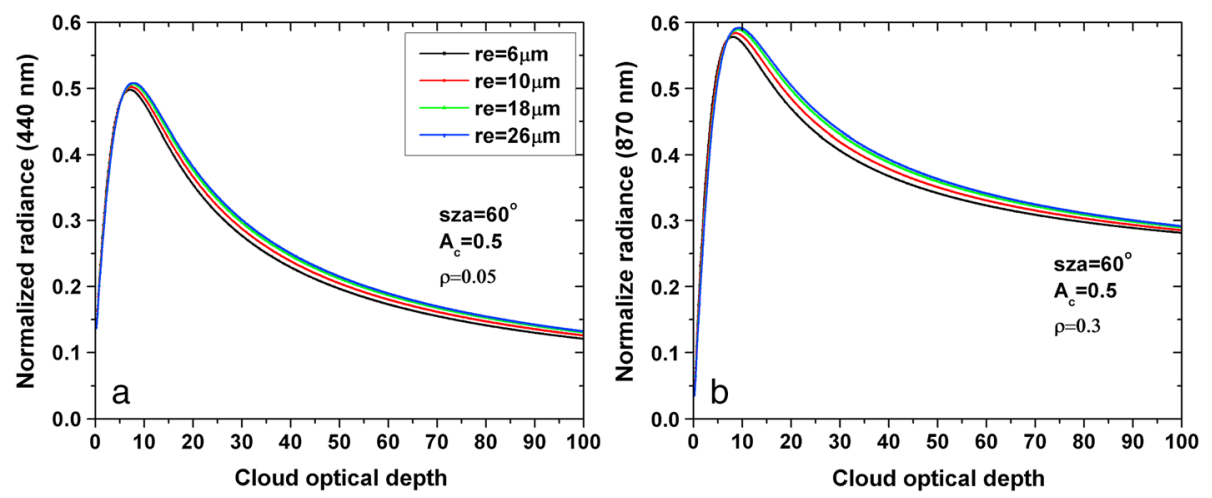

Figure 3. Normalized radiance as a function of cloud optical depth for different $R_{e}$ at (a) $440 \mathrm{~nm}$ and (b) $870 \mathrm{~nm}$. The solar zenith angle is $60^{\circ}$, the effective cloud fraction is 0.5 , and the surface albedo at $440 \mathrm{~nm}$ $(870 \mathrm{~nm})$ is $0.05(0.3)$.

\subsection{Retrieval Methods of Cloud Parameters}

\subsubsection{COD}

[15] Methods to estimate COD based on ground remote sensing have been established. One method uses direct radiance measurements but must take into account multiple forward scattering and is confined to a rather small upper limit of COD [Min et al., 2004; Wang and Min, 2008]. Another approach for inferring COD uses downwelling fluxes measured by pyranometers in the $0.3-3.0 \mu \mathrm{m}$ region of the solar spectrum [Leontieva et al., 1994; Boers, 1997; Barker et al., 1998] or measured at one or at several wavelengths in the visible and/or near-infrared spectral region [Min and Harrison, 1996; Leontieva and Stamnes, 1996]. This method is valid for a plane-parallel, homogeneous atmosphere above a uniform surface, but it fails under broken cloud sky conditions under which the retrieval may be regarded as an "effective" COD rather than a "local," or overhead, COD [Chiu et al., 2006; Boers et al., 2010].

[16] Another method to derive a local estimate of COD uses zenith radiances measured by a narrow FOV radiometer [Marshak et al., 2000; Barker and Marshak, 2001; Marshak et al., 2004]. However, due to the lack of a one-to-one relationship between zenith radiances and COD, an unambiguous retrieval is impossible from single-wavelength measurements. Based on the significant contrast in surface albedo between the visible spectral region $(400-680 \mathrm{~nm})$ and the near-infrared region (780-2500 nm) for a vegetated surface, some studies used zenith radiances at $870 \mathrm{~nm}$, along with 440 or $673 \mathrm{~nm}$, to retrieve COD in order to reduce the retrieval ambiguity [Marshak et al., 2000; Barker and Marshak, 2001; Marshak et al., 2004; Chiu et al., 2006; Chiu et al., 2010a]. McBride et al. [2011] demonstrated that a combination of multiple wavelengths that have different water absorptions could be also used to retrieve COD. Some suggested using the spectrally invariant behavior of zenith radiances for retrieving cloud properties in areas near cloud edges [Marshak et al., 2008; Chiu et al., 2010b]. To take advantage of high-quality measurements from AERONET (see section 2.1), we adopted the method that uses measurements at 440 and $870 \mathrm{~nm}$ and that is applicable for both overcast and broken cloud scenes over a vegetated surface [Chiu et al., 2010a]. A brief review of the method is given here.

[17] Any ground measurement of radiance, $I$, can be represented as the sum of the radiation calculated for a nonreflecting surface, $I_{0}$, and the radiation due to surface-cloud interactions [Box et al., 1988; Barker and Marshak, 2001]:

$$
\begin{gathered}
I=I_{0}+\frac{\rho T_{0} I_{s}}{1-\rho R} \\
T_{0}=1-A_{c}-T_{0 p p} A_{c},
\end{gathered}
$$

where $\rho$ is the albedo of the underlying Lambertian surface; $T_{0}$ is the transmittance for a nonreflecting surface; $I_{s}$ is the radiance of a radiation field generated by an isotropic source, $1 / \pi$, located at the surface; $R$ is the spherical albedo isotropically reflected from below clouds; $A_{c}$ is an effective cloud fraction; and $T_{0 p p}$ is the plane-parallel transmittance for a nonreflecting surface. So for a given wavelength, the ground-based measurement of radiance can be expressed as follows:

$$
I_{\lambda}\left(\tau, A_{c}\right)=I_{0, \lambda}(\tau)+\frac{\rho_{\lambda} I_{s, \lambda}(\tau) \cdot\left[1-A_{c}+A_{c} T_{0 p p, \lambda}(\tau)\right]}{1-\rho_{\lambda} R_{\lambda}(\tau)} .
$$

[18] Here, $\tau$ is the COD. In our study, the surface albedo is estimated from MODIS-Terra/Aqua combined data at $500 \mathrm{~m}$ resolution (Collection 5 products) [Schaaf et al., 2002] and $I_{\lambda}$ is calculated using the discrete-ordinate radiative transfer model [Stamnes et al., 1988] with the assumption that $\mathrm{R}_{\mathrm{e}}$ is equal to $8 \mu \mathrm{m}$. It is reasonable to assume a typical value of $\mathrm{R}_{\mathrm{e}}$ because there is no significant dependence between COD and assumed $\mathrm{R}_{\mathrm{e}}$, based on zenith radiance measurements (Figure 3). A 5\% (25\%) uncertainty in zenith radiance measurements $\left(R_{e}\right)$ leads to a $5-10 \%(4 \%)$ error in COD retrievals. A $10 \%$ and $5 \%$ uncertainty in surface albedo at 440 and $870 \mathrm{~nm}$, respectively, results in errors of $1-3 \%$ in COD retrievals. In total, the uncertainty in COD retrievals can reach 17\% [Chiu et al., 2010a]. Aerosol loading varies greatly over time at the site, so aerosol contamination was not considered in this study. Previous work showed that aerosol contamination was important to consider when COD was less than 3 [Beaulne et al., 2005], so only cases where COD is greater than 3, accounting for $\sim 90 \%$ of total cases, are analyzed here.

[19] During the field campaign, the COD under overcast condition was also retrieved from ground-based flux measurements made by the MFRSR. One-minute averages of total transmittance at $415 \mathrm{~nm}$, together with 1-D radiative transfer theory, were used to retrieve COD, which is similar to the method proposed by Min and Harrison [1996]. 

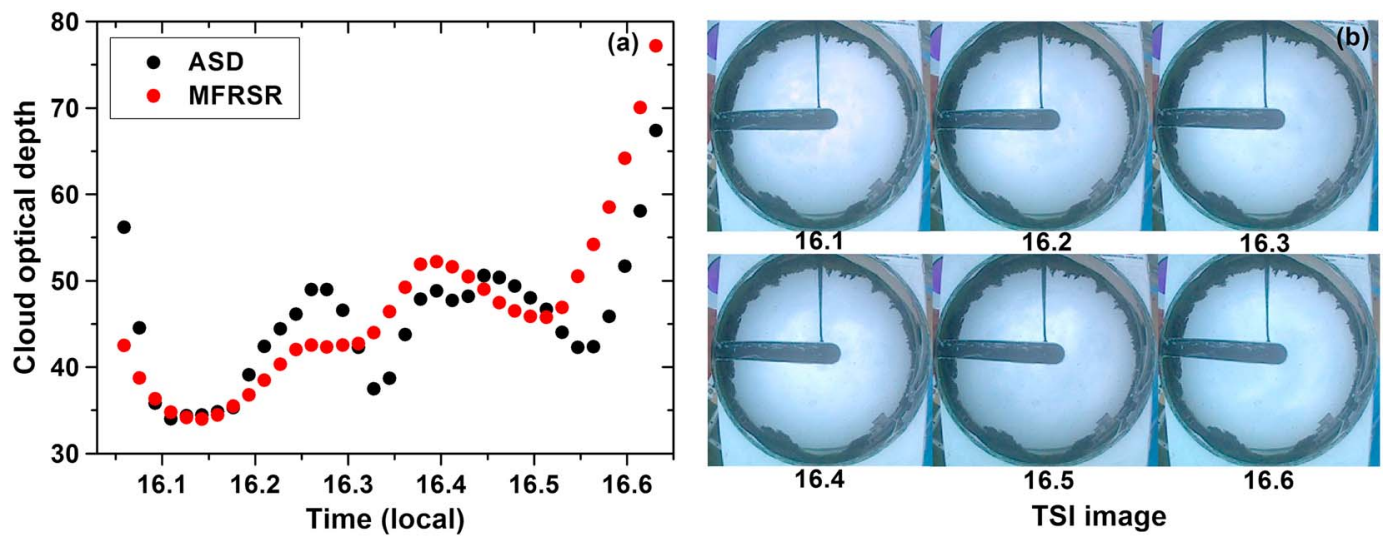

Figure 4. (a) Time series of matched MFRSR (red dots) and ASD spectroradiometer (black dots) retrievals of cloud optical depth made on 15 August 2008 and (b) TSI snapshots of the sky during the time period shown.

\subsubsection{LWP}

[20] The retrieval method of LWP is a statistical approach that uses opacities, surface pressure, temperature, and relative humidity to retrieve vertical profiles of temperature and humidity, as well as integrated water vapor column amount and LWP [Liljegren and Lesht, 2004]. Retrieval coefficients are derived for each season to account for seasonal variations in the atmosphere and in the mean radiating temperature. Because radiosondes were not launched at the site where the radiometer was located, the statistical ensemble used to derive retrieval coefficients included radiosondes launched at Hangzhou, Shanghai, and Nanjing. In our study, opacities computed from measured brightness temperatures at the five K-band channels $(22.235,23.035,23.835,26.235$, and $30.0 \mathrm{GHz}$ ) were used to retrieve LWP as described by Liljegren and Lesht [2004]. Uncertainties in the LWP may be due to several factors, including biases in the calibration, uncertainties in the modeling of the atmospheric gaseous absorption, or biased radiosonde soundings. The typical uncertainty in LWP retrievals from microwave radiometers is $\sim 20 \mathrm{~g} / \mathrm{m}^{2}$ for $\mathrm{LWP}<200 \mathrm{~g} / \mathrm{m}^{2}$ and $\sim 10 \%$ for LWP $>200 \mathrm{~g} / \mathrm{m}^{2}$ [Dong et al., 2000; Liljegren et al., 2001]. However, this theoretical uncertainty does not include calibration and model biases. The presence of unaccounted biases in the retrieval would result in a biased estimate of $R_{e}$. To evaluate the presence of biases, a distribution of LWP retrieved during clear-sky cases was produced. Under clear-sky conditions, the mean of the distribution was $0.8 \mathrm{~g} / \mathrm{m}^{2}$ with a standard deviation of $13 \mathrm{~g} / \mathrm{m}^{2}$. Therefore, there were no appreciable biases in the retrievals during the deployment.

[21] LWP retrievals during rain or when the window of the MWRP was wet are discarded. Similarly, LWP values less than $20 \mathrm{~g} / \mathrm{m}^{2}$ (when retrieval errors are large) or greater than $700 \mathrm{~g} / \mathrm{m}^{2}$ (when there is probably precipitation contamination [Dong et al., 2008]) are disregarded.

2.2.3. $\mathbf{R}_{\mathrm{e}}$

[22] $R_{e}$ is retrieved from the ASD spectroradiometerretrieved $\operatorname{COD}(\tau)$ values and MWRP-retrieved LWP values based on the following equation:

$$
\tau=\frac{3 \mathrm{LWP}}{2 \rho_{w} R_{e}},
$$

where $\rho_{w}$ is the density of water. In order to retrieve $\mathrm{R}_{\mathrm{e}}$, MWRP and ASD spectroradiometer measurements were matched temporally. The MWRP can retrieve LWP during the day and at night, while COD retrievals rely on measurements of solar radiance. Therefore, our analysis is limited to the daytime. This $\mathrm{R}_{\mathrm{e}}$ retrieval method was also used in the study by McComiskey et al. [2009], which is based on the COD retrieved from the two-channel narrow FOV radiometer [Chiu et al., 2006] and LWP retrieved from a microwave radiometer [Liljegren and Lesht, 2004].

\section{Results}

\subsection{Intercomparisons of the Retrievals of Cloud Properties From Different Ground- and Satellite- Based Measurements}

\subsubsection{Comparison With MFRSR COD Retrievals}

[23] Figure 4 shows the time series of matched COD retrievals from the ASD spectroradiometer and the MFRSR on 15 August 2008, as well as total sky imager TSI images of the overcast sky. Although mean CODs from both retrievals are close in magnitude (45.1 \pm 7.3 and $46.3 \pm 9.9$ from ASD spectroradiometer and MFRSR retrievals, respectively), differences are seen in the instantaneous values. Much more variation over time is seen in the ASD spectroradiometer retrievals. This is mainly due to differences in the FOV of the two instruments. MFRSR retrievals represent a hemispherical mean value from the cloud deck overhead, while ASD spectroradiometer retrievals sample that part of the cloud deck immediately overhead. Thus, ASD spectroradiometer retrievals show much finer spatial variability than the hemispheric counterpart.

[24] Further analysis of ASD spectroradiometer and MFRSR COD retrievals was performed following the method of Chiu et al. [2010a]. An overcast period is defined when MFRSR COD retrievals are continuously greater than five for at least $1 \mathrm{~h}$. Rainy overcast periods were excluded by monitoring precipitation using the rainfall sensor on the Vaisala WXY510 weather transmitter installed at the site and the integral rain sensor located on the MWRP. Figure 5 shows a comparison of simultaneous estimates of COD from ASD spectroradiometer retrievals and from the collocated MFRSR for all overcast cases. Most of the points fall close to the $1: 1$ line, and more than $60 \%$ of the retrievals agree to within $20 \%$. Correlation coefficient $\left(\mathrm{R}^{2}\right)$ and the root mean square deviation are 0.82 and 5.96, respectively. The mean COD from all instantaneous ASD spectroradiometer and 


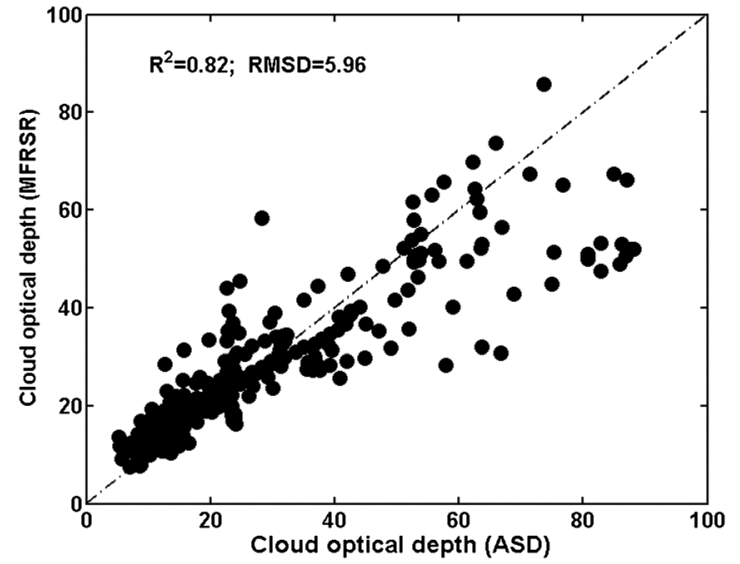

Figure 5. Scatterplot of instantaneous MFRSR and ASD spectroradiometer cloud optical depth retrievals for all overcast cases.

MFRSR retrievals is $23.9 \pm 18.2$ and $24.0 \pm 13.4$, respectively. The larger standard deviation seen in ASD spectroradiometer retrievals is reasonable because given the much finer spatial resolution of the ASD spectroradiometer, greater variations in clouds are captured, as suggested by the case study shown in Figure 4. Overall, these results are satisfactory given that the two retrieval methods use completely different radiative quantities to retrieve COD (point-wise zenith radiance versus hemispherical flux).

\subsubsection{Comparison With MODIS Retrievals}

[25] For intercomparisons between ground- and satellitebased data, the temporal and spatial scales of the two sets of measurements should be matched as closely as possible. To maximize the number of ground-based sample points and to avoid using too many satellite pixels, a $1 \mathrm{~h}$ time interval centered at the time of a MODIS overpass is used [Dong et al., 2008]. MODIS provides the cloud optical and microphysical properties at a $1 \mathrm{~km}$ resolution, and retrievals from pixels falling within $2 \mathrm{~km}$ of Taihu were selected. Only nonprecipitating and overcast liquid water cloud retrievals were considered. TSI images were browsed to identify potential overcast cases. In total, there were 11 cases where ASD spectroradiometer and MWRP retrievals were collocated with a MODIS-Terra overpass and eight cases where ASD spectroradiometer and MWRP retrievals were collocated with a MODIS-Aqua overpass.

[26] Figure 6 shows comparisons of ground- and MODISbased retrievals of LWP, COD, and $\mathrm{R}_{\mathrm{e}}$. The top panels are for MODIS-Terra and the bottom panels are for MODIS-Aqua. The horizontal bar represents the standard deviations of surface retrievals computed from retrievals made within $1 \mathrm{~h}$ of the satellite overpass time, and the vertical bar represents the MODIS mean retrieval uncertainty. On average, relative to surface retrievals, the mean LWP and COD retrieved from MODIS-Terra are smaller by $33.6 \mathrm{~g} / \mathrm{m}^{2}$ and 5.8 , respectively. The mean $R_{\mathrm{e}}$ is larger by $2.9 \mu \mathrm{m}$. In terms of relative differences, expressed as [(MODIS-surface)/surface] $\times 100 \%$, they are $-26.4 \%,-31.4 \%$, and $29.3 \%$ for LWP, COD, and $\mathrm{R}_{\mathrm{e}}$, respectively. For MODIS-Aqua, their mean retrieved biases are $-43.3 \mathrm{~g} / \mathrm{m}^{2},-3.0$, and $-1.3 \mu \mathrm{m}$, and relative differences are $-22.3 \%,-10.0 \%$, and $-12.0 \%$, respectively. On average, the total difference between COD retrieved from the ASD spectroradiometer and MODIS overpasses is about $-20.7 \%$, similar to the difference found by Yang et al. [2008]. Typically, satellite-retrieved values of $R_{e}$ are representative of cloud particle sizes near the top of optically thick clouds [Chang and $L i, 2002,2003$ ], while the surface-retrieved $\mathrm{R}_{\mathrm{e}}$, weighted by water mass in the cloud, represents the layer mean particle size [Dong et al., 2008].This is likely one cause for the systematic difference between $\mathrm{R}_{\mathrm{e}}$ retrieved from MODIS and from surface instrumentation. Retrieval errors in COD and/or $R_{e}$ lead to large errors in LWP
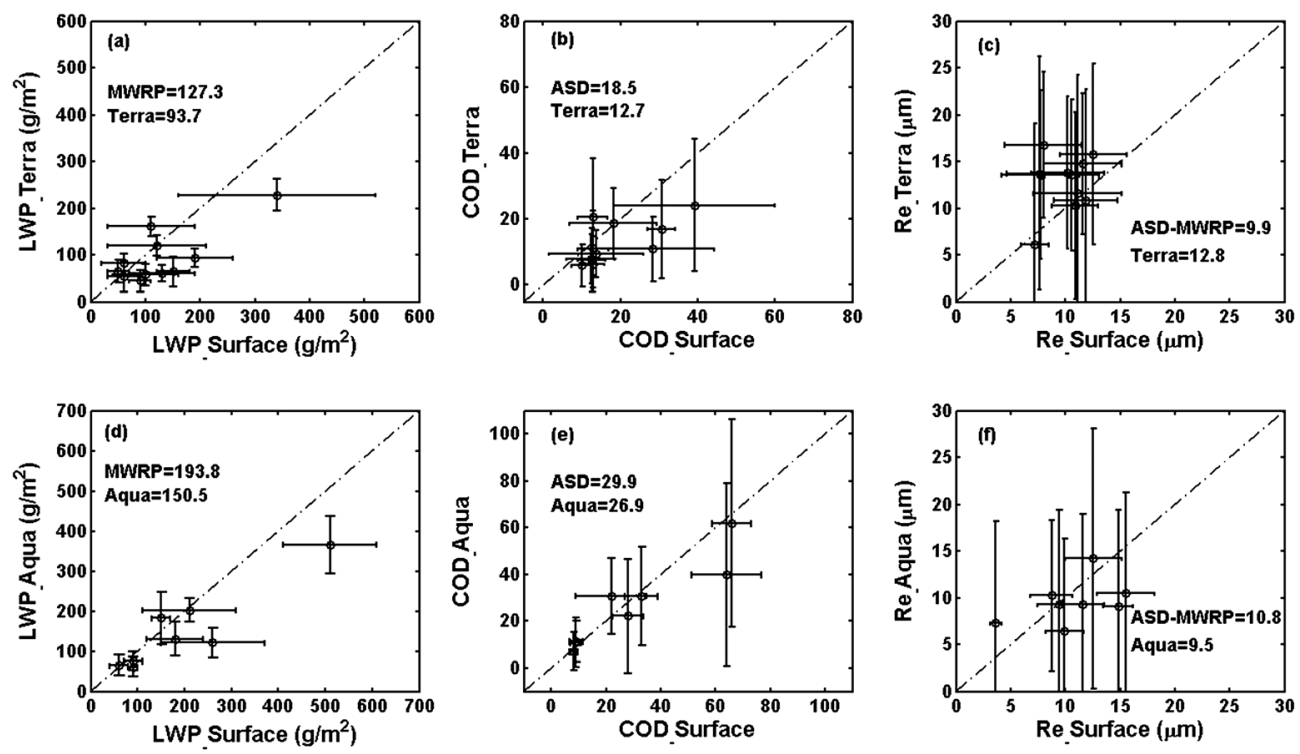

Figure 6. Comparison of retrievals from surface measurements and (a-c) MODIS-Terra/(d-f) MODISAqua of liquid water path, cloud optical depth, and effective radius. The horizontal bars in each plot are the standard deviations of surface measurements during the $1 \mathrm{~h}$ time window centered at the MODIS overpass time, and vertical bars represent the MODIS mean retrieval uncertainty. Overall mean values of the cloud parameters are listed in each plot. 


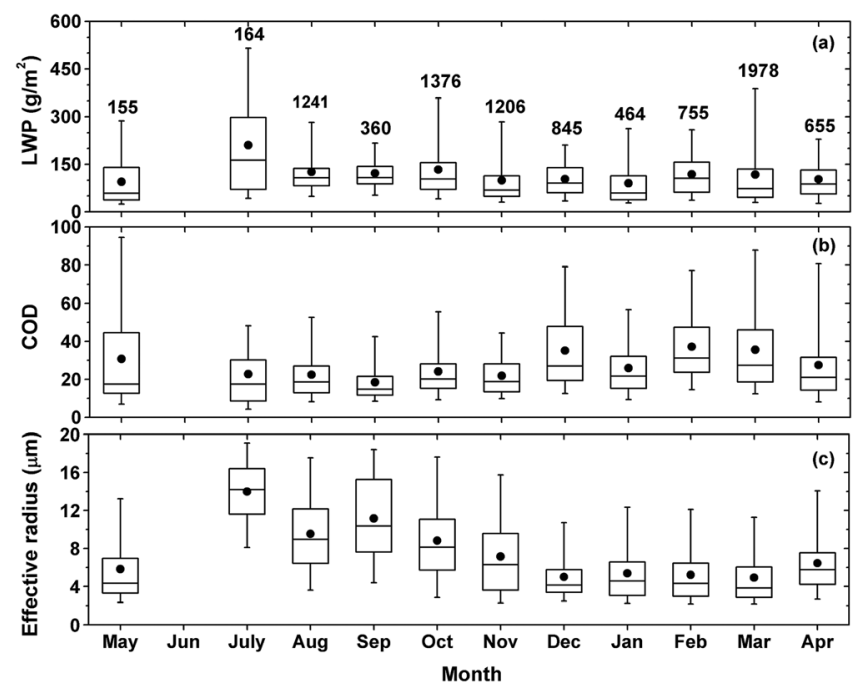

Figure 7. Monthly statistical characteristics of (a) liquid water path, (b) cloud optical depth, and (c) effective radius. Box-and-whisker plots include the median (middle of the box), 25th and 75th percentiles (ends of the box), 5th and 95th percentiles (ends of the whiskers), and means (black dots). The sample numbers in each month are shown on the top of each box.

compared to LWP retrievals from surface-based MWRP measurements. Meanwhile, the satellite-based LWP retrievals based on the COD and $\mathrm{R}_{\mathrm{e}}$ are also influenced by the vertical variation of cloud droplet size [Chen et al., 2007]. Relatively large biases between LWP retrieved from MODIS and from a satellite-borne microwave imager over the ocean were also found by Horváth and Davies [2007], whose study reported an instantaneous uncertainty of $35 \%$ for boundary layer clouds and an uncertainty of $5-10 \%$ on average. However, these biases vary with the subdomain cloud fraction; the mean LWP from MODIS tends to be higher than that from microwave imagers for strictly overcast domains [Horváth and Davies, 2007]. The cloud top structure also influences satellite retrievals. It will cause three-dimensional effects that result in reflectance patterns that deviate from the plane-parallel model used in satellite retrievals [Dong et al., 2008]. Some other factors influencing the comparison between retrievals of cloud parameters from satellite and from the surface are discussed by Dong et al. [2008], for example, mismatching in terms of the actual portions of cloud that are sampled and viewing and illumination angles of the satellite. Nevertheless, MODIS cloud retrievals are problematic over this part of the world, and more work is needed to assess and improve the retrieval of cloud properties in this region. Despite the potential problems, it is encouraging that almost all COD and $\mathrm{R}_{\mathrm{e}}$ derived from ASD spectroradiometer and combined ASD spectroradiometer and MWRP measurements fall within the MODIS "uncertainty range" (Figure 6).

[27] The results presented here represent only liquid water clouds under overcast conditions. Without additional comparisons, it is not clear whether the current finding is representative of other cases over this region. The comparison between satellite and ground instrument retrievals includes a small enough sample size that a significant number of other criteria could be considered when analyzing these results, e.g., the solar angle [Várnai and Marshak, 2002], the viewing angle [Maddux et al., 2010], multilayer versus single-layer cloud scenes, cloud top heterogeneity, seasons, and even day and night. However, up until now, ground data are still currently limited geographically and temporally to a few types of clouds over particular areas or limited to case studies [Dong et al., 2008]. A complete quantitative
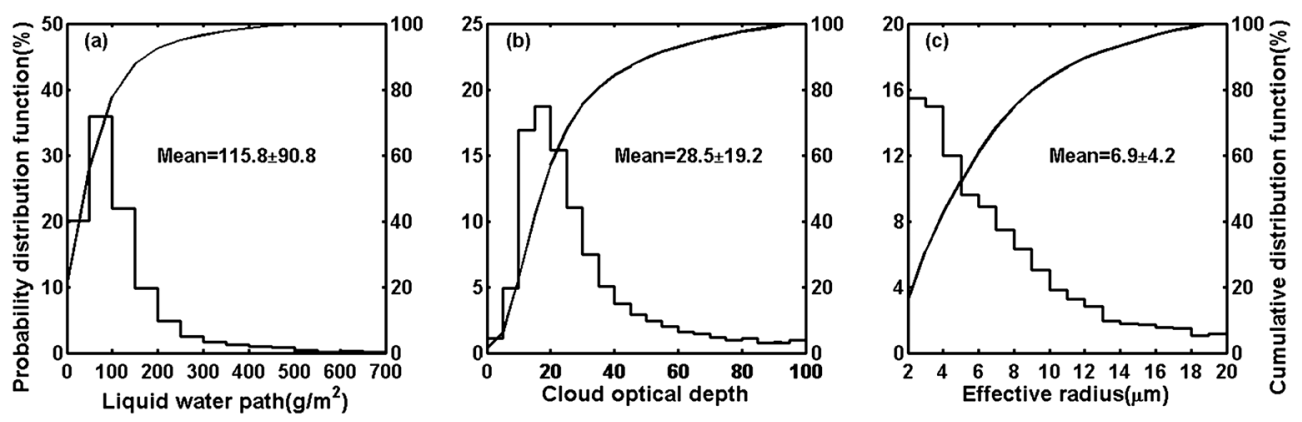

Figure 8. Probability distribution functions (PDF) (horizontal steps) and cumulative distribution functions (CDF) (solid lines) for (a) liquid water path, (b) cloud optical depth, and (c) effective radius using 1 year's worth of observations. Numbers in each panel are the annual mean plus/minus the standard deviation of the mean. 

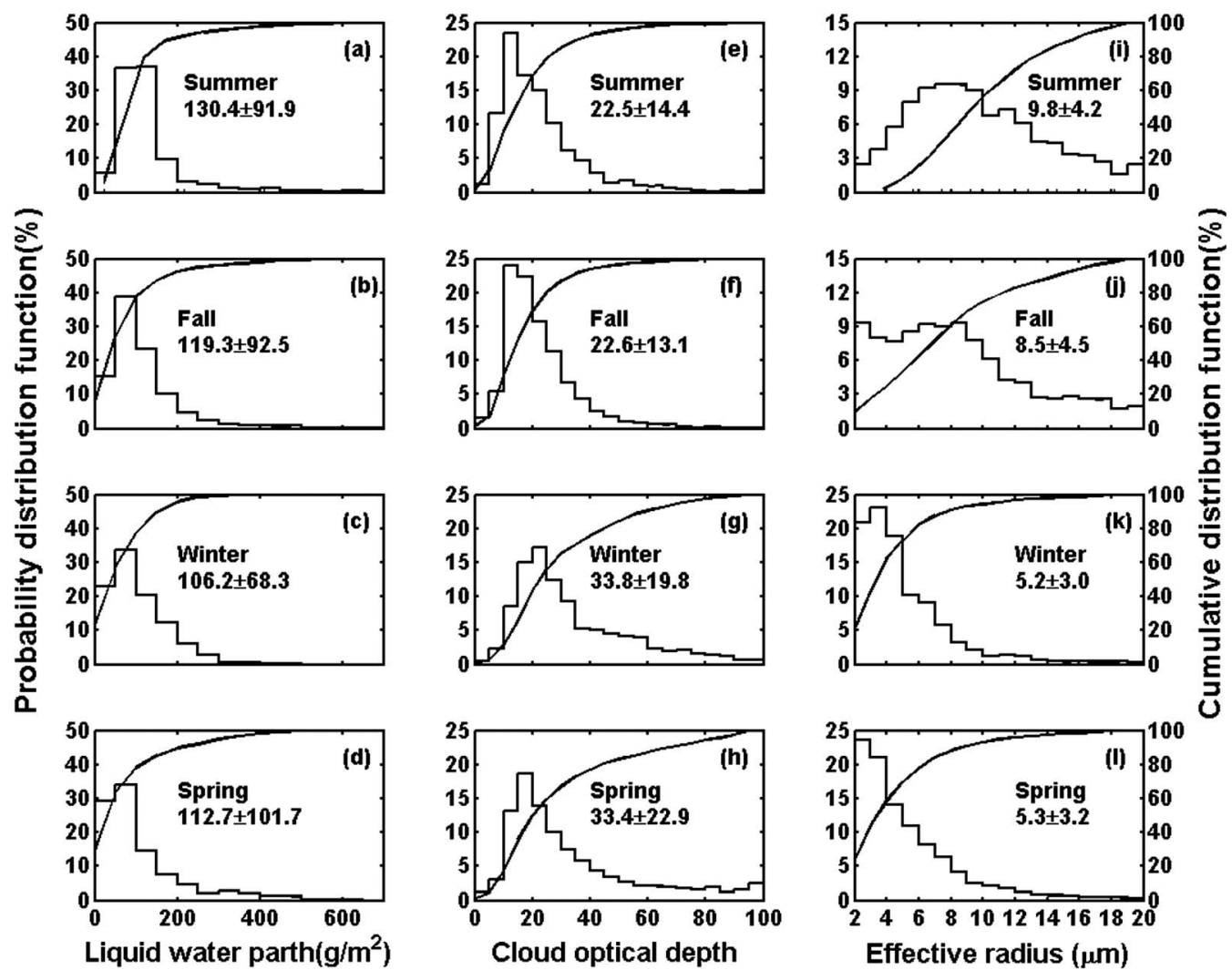

Figure 9. Probability distribution functions (PDF) (horizontal steps) and cumulative distribution functions (CDF) (solid lines) for (a-d) liquid water path, $(\mathrm{e}-\mathrm{h})$ cloud optical depth, and (i-l) effective radius in summer, fall, winter, and spring, respectively. Numbers in each panel are the seasonal mean plus/minus the standard deviation of the mean.

assessment requires more independent samples for each condition. A complete validation of cloud retrievals made under all conditions will take many years to achieve and will proceed in steps for particular conditions using available reference data sets [Dong et al., 2008]. An effort is ongoing to address some of these validation concerns, but a lack of enough samples hampers this effort.

\subsection{Seasonal Variation of Cloud Properties}

[28] Statistical characteristics of all three cloud properties, based on measurements from the ASD spectroradiometer and the MWRP, are analyzed. Nonprecipitating clouds with CODs greater than 3.0 and with LWP ranging from 20 to $700 \mathrm{~g} / \mathrm{m}^{2}$ are considered here. One full year's worth of data is available for this analysis (May 2008 to April 2009). While it cannot provide any climatological features of cloud properties, it may shed a little light on their seasonal variations.

[29] Figure 7 shows box-and-whisker plots of monthly statistical characteristics of LWP, COD, and $\mathrm{R}_{\mathrm{e}}$. The bottom and top of each box represent the 25 th and 75 th percentiles of the distribution, the bottom and top of the whiskers represent the 5th and 95th percentiles of the distribution, and horizontal lines and black dots inside each box represent median and mean values, respectively. The numbers on the top of each box indicate the samples in each month. The probability distribution function (PDF) and cumulative distribution function $(\mathrm{CDF})$ of cloud properties throughout the whole year and for each season are illustrated in Figures 8 and 9, respectively. Figure 7 a shows that LWP reaches a maximum in July and is smallest during the winter; this is partly due to the water vapor amount in the atmosphere during these seasons (see Figure 10 for mean relative humidity fields derived from the National Centers for Environmental Prediction (NCEP)/ National Center for Atmospheric Research (NCAR) reanalysis at 850 mbar over the period of May 2008 to April 2009). The annual mean (median) LWP is $115.8 \pm 90.8(90.4) \mathrm{g} / \mathrm{m}^{2}$, with seasonal means (medians) of $130.4 \pm 91.9$ (107.8), $119.3 \pm 92.5$ (93.5), $106.2 \pm 68.3(87.0)$, and $112.7 \pm 101.7$ $(76.8) \mathrm{g} / \mathrm{m}^{2}$ in summer, fall, winter, and spring, respectively. More than $90 \%$ of LWP values for the whole year and in each season have values smaller than $250 \mathrm{~g} / \mathrm{m}^{2}$, with peaks between 50 and $150 \mathrm{~g} / \mathrm{m}^{2}$ in the summertime and between 50 and $100 \mathrm{~g} / \mathrm{m}^{2}$ in the other seasons, as shown in Figures $8 \mathrm{a}$ and $9 \mathrm{a}-9 \mathrm{~d}$.

[30] Monthly mean COD is smallest during summer and fall $(22.5 \pm 14.4$ and $22.6 \pm 13.1$, respectively) and is largest in winter and spring $(33.8 \pm 19.8$ and $33.4 \pm 22.9$, see Figure 7b). The median COD is $18.6,19.1,27.5$, and 25.1 in summer, fall, winter, and spring, respectively. Although the LWP and COD generally change consistently, their seasonal maximum does not fall in the same season because of the nonlinear relationship between the two. An additional explanation for the inconsistency between the LWP and the COD could be the larger summer values of $R_{e}$ (as reflected by the seasonal average) than the winter values (Figures $9 \mathrm{i}$ 


\section{LIU ET AL.: CLOUD PROPERTIES IN EASTERN CHINA}

(a) Summer

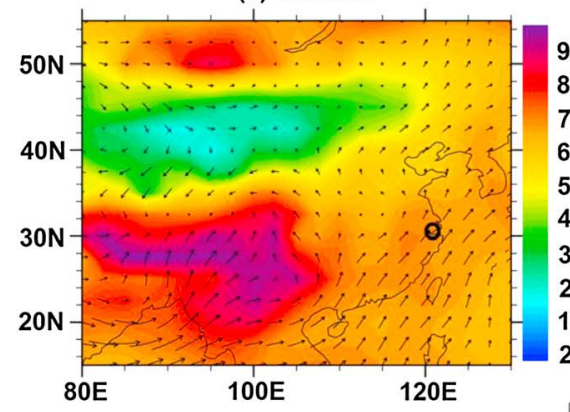

(c) Winter

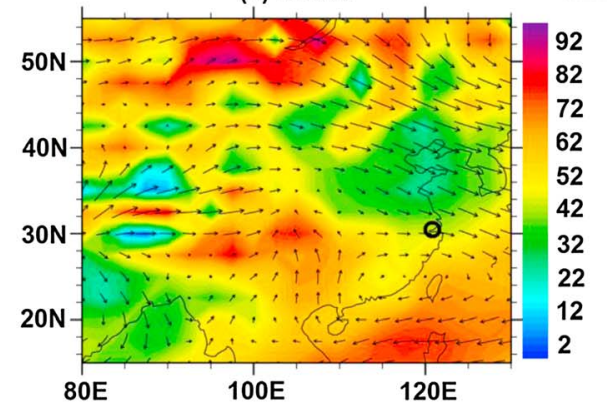

(b) Fall

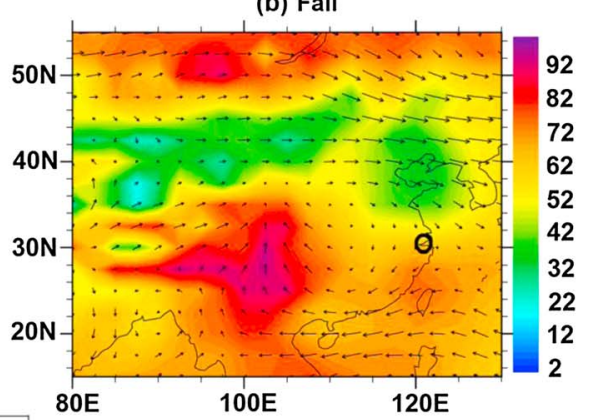

(d) Spring

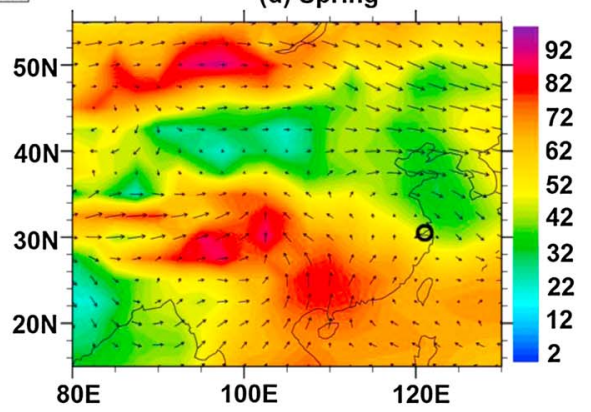

Figure 10. Seasonal mean relative humidity fields (colored background) and wind speed/direction distributions (arrows) derived from the NCEP/NCAR reanalysis at the $850 \mathrm{hPa}$ pressure level from May 2008 to April 2009: (a) summer, (b) fall, (c) winter, and (d) spring. The black circle in each plot shows the location of Taihu.

and 9k). The annual mean (median) COD during our study period is $28.5 \pm 19.2(22.4)$, and most of the COD values $(>90 \%)$ are between 5 and 60, with peaks between 15 and 20 for the whole year (Figure 8b). Figures 9e-9h show the PDF and CDF of COD for each season. Approximately $90 \%$ of COD values are less than 40 in the summertime and in fall; peaks are found between 15 and 20. For the other seasons, most of the COD values are less than 65 (winter) and 75 (spring); peaks are found between 20 and 25 (winter) and 15 and 20 (spring). From 6 years of ground-based measurements of midlatitude continental clouds in the southern Great Plains $\left(36.6^{\circ} \mathrm{N}, 97.5^{\circ} \mathrm{W}\right)$, Dong et al. [2005] found that the seasonally minimum COD and LWP occurred in the summertime, while seasonally maximum COD and LWP occurred in spring and fall, respectively, which also illustrates the inconsistent variation in COD and LWP.

[31] Figure 7c shows that $R_{e}$ varies noticeably from season to season. The annual mean (median) $\mathrm{R}_{\mathrm{e}}$ during our study period is $6.9 \pm 4.2(5.8) \mu \mathrm{m}$ with seasonal means (medians) of $9.8 \pm 4.2(9.2), \quad 8.5 \pm 4.5 \quad(7.8), \quad 5.2 \pm 3.0 \quad(4.2)$, and $5.3 \pm 3.2(4.3) \mu \mathrm{m}$ in summer, fall, winter, and spring, respectively. The $\mathrm{R}_{\mathrm{e}}$ in summer is larger than that in winter because of the following likely physical reasons. Assuming that the number of cloud condensation nuclei is the same during summer and winter, the greater amount of water vapor in the summertime atmosphere (Figure 10) and stronger convection foster the growth of cloud droplets. Mean droplet sizes increase monotonically with height above a cloud base, for a growth process dominated by condensation rather than coalescence. So larger cloud droplets might be expected to occur in the geometrically thicker clouds observed during summer [Dong et al., 2000]. Approximately $80 \%$ of $\mathrm{R}_{\mathrm{e}}$ values are smaller than $10 \mu \mathrm{m}$ with peaks between 2 and $4 \mu \mathrm{m}$ for the whole year period (Figure 8c). The PDF and CDF for each season in Figures $9 \mathrm{i}-91$ show that $\mathrm{R}_{\mathrm{e}}$ distributions are broader in summer and fall than in winter and spring, presumably related to the seasonal variation of convection. The convection is stronger in summer and fall than
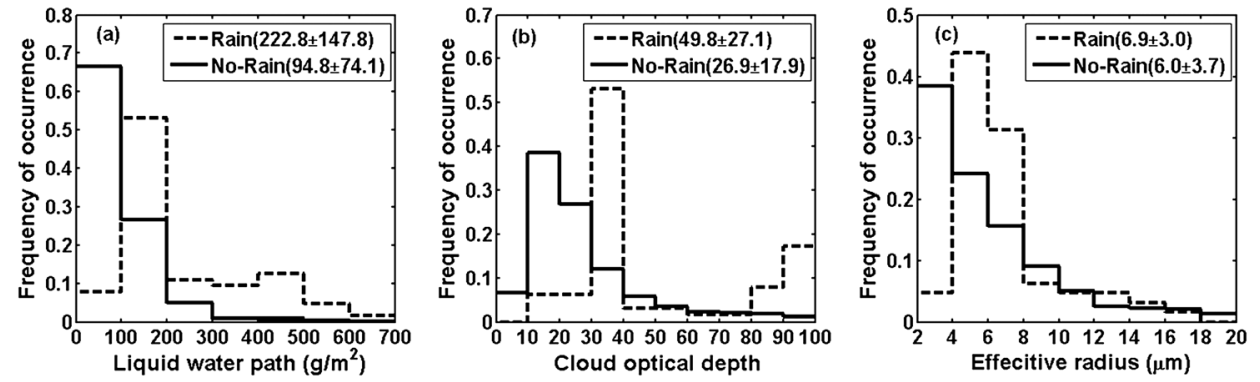

Figure 11. Distribution of surface-retrieved (a) liquid water path, (b) cloud optical depth, and (c) cloud particle effective radius with mean values of each parameter for raining clouds and nonraining clouds. 
in winter and spring with the seasonally mean convective available potential energy (CAPE) of 733.6 and $107.8 \mathrm{~J} / \mathrm{kg}$ in summer and fall, and 22.5 and $59.3 \mathrm{~J} / \mathrm{kg}$ in winter and spring, respectively. The seasonally mean CAPE was calculated from the European Centre for Medium-Range Weather Forecasts reanalysis data, which were averaged within $a 1^{\circ} \times 1^{\circ}$ area centered on the Taihu site. The distributions of $\mathrm{R}_{\mathrm{e}}$ in summer and fall have a much longer tail trailing toward higher values with more values falling in the range of 6-10 $\mu \mathrm{m}$ (summer) and 2-10 $\mu \mathrm{m}$ (fall). Roughly $80 \%$ of $\mathrm{R}_{\mathrm{e}}$ values are smaller than $7 \mu \mathrm{m}$ in winter and spring with peaks between 3-4 $\mu \mathrm{m}$ and 2-3 $\mu \mathrm{m}$, respectively.

\subsection{Cloud Properties for Raining Clouds and Nonraining Clouds}

[32] Based on 1 year's worth of cloud optical and microphysical data retrieved from surface measurements, differences in cloud optical and microphysical parameters between raining and nonraining clouds, as well as the relationship between these cloud parameters and rainfall frequency over the site, were also examined, as a validation of a finding from a satellite-based study [Chen et al., 2011]. Cloud properties of raining clouds are defined as the retrieved cloud properties during the $1 \mathrm{~h}$ period before rainfall occurs. The rainfall frequency is calculated as the ratio of the number of rain events divided by the total number of observations, regardless of rain duration. Cloud parameters for nonraining clouds were obtained from the retrievals when no rain was detected during a day of observation. Figure 11 shows the frequency of occurrence distribution of $L W P, C O D$, and $R_{e}$ with the mean value of each parameter for raining clouds and nonraining clouds. Relatively large differences in mean values of LWP and COD and relatively small differences in mean $R_{e}$ for raining clouds and nonraining clouds are seen. Figures $11 \mathrm{a}$ and $11 \mathrm{~b}$ indicate that clouds with large LWP and/or COD are more likely to rain. Most (approximately 70\%) nonraining clouds have LWP values smaller than $100 \mathrm{~g} / \mathrm{m}^{2}$, and more than $72 \%$ of nonraining clouds have COD values smaller than 30 . There is no significant difference in the frequency of occurrence of $R_{e}$ when $R_{e}$ values are larger than $8 \mu \mathrm{m}$ for raining clouds and nonraining clouds (Figure 11c). Meanwhile, the statistical relationship between the cloud optical and microphysical parameters showed that LWP has the best correlation with rainfall frequency with a correlation coefficient $\left(\mathrm{R}^{2}\right)$ of 0.62 , followed by COD and $R_{e}$ with $R^{2}$ values of 0.40 and 0.05 , respectively. The results corroborate the finding of Chen et al. [2011] for warm rain over oceans using A-Train satellite data.

[33] LWP has the best correlation with rainfall frequency because LWP directly reflects the total amount of liquid water in clouds. The LWP of nonprecipitating clouds decreases with aerosol loading, while the LWP of transitional and precipitating clouds increases dramatically with aerosol loading [Lebsock et al., 2008]. This sharp and contrasting influence of aerosols on LWP between nonprecipitating and precipitating clouds will increase the difference in LWP for raining and nonraining clouds under high-aerosol conditions, implying that the contribution of LWP on rainfall frequency will be enhanced. COD is correlated with rain because a cloud with a large optical depth is generally thick and an optically thicker cloud generally has a longer path and more liquid water for sustaining the coalescence process [Chen et al., 2011].
$R_{e}$ has a positive relationship with rainfall frequency because $\mathrm{R}_{\mathrm{e}}$ is associated with the droplet effective radius. While combing through CloudSat and MODIS satellite retrievals, Suzuki et al. [2010] found that the raindrop collection efficiency increases with droplet effective radius. As stated in section 3.1.2, $\mathrm{R}_{\mathrm{e}}$ retrievals based on satellite measurements are significantly weighted toward the cloud top and are representative of cloud particle sizes near the top of optically thick clouds, while LWP and COD satellite retrievals are path-integrated quantities. This may partially explain why LWP and COD have better correlations with rainfall frequency than does $\mathrm{R}_{\mathrm{e}}$ [Stephens and Haynes, 2007; Chen et al., 2011]. However, our results show that this may not be the reason, or at least may not be the major reason, why $\mathrm{R}_{\mathrm{e}}$ has the smallest correlation with rainfall frequency because the $R_{e}$ retrieved in our study is also representative of path-integrated quantities. This finding is more confirmation that clouds with larger LWP are more likely to produce rain and also implies that further studies are still needed to discover physical reasons explaining why $\mathrm{R}_{\mathrm{e}}$ has less correlation.

\section{Summary}

[34] During the East Asian Studies of Tropospheric Aerosols and their Impact on Regional Climate (EAST-AIRC) campaign that ran from May 2008 to December 2009, a series of instruments, including a high-resolution Analytical Spectral Devices (ASD) spectroradiometer, a microwave radiometer profiler (MWRP), and a multifilter rotating shadowband radiometer (MFRSR), were installed at a site located in the Yangtze Delta region of China. Comprehensive surface-based retrievals of cloud optical and microphysical properties were made and compared to corresponding MODIS-Terra and MODIS-Aqua cloud property retrievals. Seasonal characteristics of cloud properties and cloud optical and microphysical parameters for raining clouds and nonraining clouds were also analyzed over this highly polluted area in southeast China.

[35] A case study where the sky is overcast shows that cloud optical depth (COD) retrievals from the ASD spectroradiometer and the MFRSR vary over time in the same general way although ASD spectroradiometer retrievals show more rapid variation due to their higher spatial resolution, indicating that zenith radiance measurements can better capture cloud temporal variation than retrievals using hemispherical fluxes. A comparison of simultaneous estimates of COD from ASD spectroradiometer retrievals and MFRSR measurements for all overcast cases shows a good agreement with $\mathrm{R}^{2}=0.82$. More than $60 \%$ of the retrievals agree to within $20 \%$ of each other.

[36] On the basis of a total of 11 overpasses from MODISTerra, on average, relative to surface measurements, the mean liquid water path (LWP) and COD retrieved from the satellite platform are smaller by $33.6 \mathrm{~g} / \mathrm{m}^{2}(-26.4 \%)$ and $5.8(-31.4 \%)$, respectively, and the mean cloud droplet effective radius $\left(\mathrm{R}_{\mathrm{e}}\right)$ is larger by $2.9 \mu \mathrm{m}(29.3 \%)$; mean biases of LWP, COD, and $\mathrm{R}_{\mathrm{e}}$ are $-43.3 \mathrm{~g} / \mathrm{m}^{2}(-22.3 \%),-3.0$ $(-10.0 \%)$, and $-1.38 \mu \mathrm{m}(-12.0 \%)$, respectively, based on retrievals from eight MODIS-Aqua overpasses. Some of the sources for the difference between MODIS and surface retrievals are discussed.

[37] Annual mean LWP, COD, and $\mathrm{R}_{\mathrm{e}}$ are $115.8 \pm 90.8 \mathrm{~g} / \mathrm{m}^{2}$, $28.5 \pm 19.2$, and $6.9 \pm 4.2 \mu \mathrm{m}$. Maximum (minimum) values of 


\section{LIU ET AL.: CLOUD PROPERTIES IN EASTERN CHINA}

LWP and $\mathrm{R}_{\mathrm{e}}$ occur in summer (winter); COD reaches its highest magnitude in winter and spring. Overall, for LWP, more than $90 \%$ of its values for the whole year and for each season are less than $250 \mathrm{~g} / \mathrm{m}^{2}$, with peaks between 50 and $100 \mathrm{~g} / \mathrm{m}^{2}$; for COD, most of its values $(>90 \%)$ fall between 5 and 60 with peaks between 15 and 20; and approximately $80 \%$ of $\mathrm{R}_{\mathrm{e}}$ values are less than $10 \mu \mathrm{m}$ with peaks between 2 and $4 \mu \mathrm{m}$ during the study period.

[38] Raining and nonraining clouds have systematic differences in mean values of LWP and COD and relatively small differences in mean $\mathrm{R}_{\mathrm{e}}$. Clouds with large COD and/or LWP are more likely to rain. LWP has the highest correlation with rainfall frequency with $R^{2}=0.62$, followed by COD and $R_{e}$ with $\mathrm{R}^{2}=0.40$ and 0.05 , respectively.

[39] These results can serve as a baseline for studying the impact of clouds on the radiation budget at the surface and within the atmosphere, when combined with satellite measurements of top-of-the-atmosphere fluxes and surface radiation measurements. Also, in combination with aerosol information, such as aerosol optical depth and aerosol extinction profiles [Liu et al., 2012], it is possible to study the impact of aerosols on cloud microphysical properties, known as aerosol indirect climate effects, one of the largest uncertainty factors in climate change studies, over this highly polluted area of southeast China. The comprehensive set of measurements and relationships reported in this study are highly valuable for testing and improving parameterization schemes concerning clouds and their interactions with atmospheric and aerosol variables.

[40] Acknowledgments. This study was supported by numerous grants from the Ministry of Science and Technology of China (2012AA120901, 2013CB955802, 2013CB955804) and National Science Foundation of China $(41175019,40637035)$ for Jianjun Liu, Fengsheng Zhao, and Zhanqing Li; the U.S. National Science Foundation (AGS1118325) for Zhanqing Li; Department of Energy (ER65319) and NASA (NNX08AH71G) for Zhanqing Li and Department of Energy (DE-SC0006001) for J. Christine Chiu; and the Key University Science Research Project of Jiangsu Province (09KJA17004) and National Natural Science Foundation of China (41075114) for Youfei Zheng. Argonne National Laboratory's work was supported by the Department of Energy, Office of Science, Office of Biological and Environmental Research, under contract DE-AC02-06CH11357.

\section{References}

Barker, H. W., and A. Marshak (2001), Inferring optical depth of broken clouds above green vegetation using surface solar radiometric measurements, J. Atmos. Sci., 58, 2989-3006.

Barker, H. W., T. J. Curtis, E. Leontieva, and K. Stamnes (1998), Optical depth of overcast cloud across Canada: Estimates based on surface pyranometer and satellite measurements, J. Climate, 11, 2980-2994.

Beaulne, A., H. W. Barker, and J. P. Blanchet (2005), Estimating cloud optical depth from surface radiometric observations: Sensitivity to instrument noise and aerosol contamination, J. Atmos. Sci., 62, 4095-4104.

Bender, F., H. Rodhe, R. Charlson, A. Ekman, and N. Loeb (2006), 22 views of the global albedo-Comparison between $20 \mathrm{GCMs}$ and two satellites, Tellus, 58A, 320-330.

Boers, R. (1997), Simultaneous retrievals of cloud optical depth and droplet concentration from solar irradiance and microwave liquid, J. Geophys. Res., 102, 2981-2989.

Boers, R., M. J. de Haij, W. M. F. Wauben, H. K. Baltink, L. H. van Ulft, M. Savenije, and C. N. Long (2010), Optimized fractional cloudiness determination from five ground-based remote sensing techniques, J. Geophys. Res., 115, D24116, doi:10.1029/2010JD014661.

Box, M. A., S. A. W. Gerstl, and C. Simmer (1988), Application of the adjoint formulation to the calculation of atmospheric radiative effects, Beitr. Phys. Atmos., 61, 303-311.

Cadeddu M. P., J. C. Liljegren, and D. D. Turner (2013), The Atmospheric Radiation Measurement (ARM) Program network of microwave radiometers:
Instrumentation, measurements and retrievals, Atmos. Meas. Tech. Discuss., 6, 3723-3763.

Chang, F. L., and Z. Li (2002), Estimating the vertical variation of cloud droplet effective radius using multispectral near-infrared satellite measurements, J. Geophys. Res., 107(D15), 4257, doi:10.1029/2001JD000766.

Chang, F. L., and Z. Li (2003), Retrieving vertical profiles of water-cloud droplet effective radius: Algorithm modification and preliminary application, J. Geophys. Res., 108(D24), 4763, doi:10.1029/2003JD003906.

Chen, R., F. L. Chang, Z. Li, R. Ferraro, and F. Weng (2007), Impact of the vertical variation of cloud droplet size on the estimation of cloud liquid water path and rain detection, J. Atmos. Sci., 64, 3843-3853.

Chen, R., Z. Li, R. J. Kuligowski, R. Ferraro, and F. Weng (2011), A study of warm rain detection using A-Train satellite data, Geophys. Res. Lett., 38, L04804, doi:10.1029/2010GL046217.

Chiu, J. C., A. Marshak, Y. Knyazikhin, W. Wiscombe, H. Barker, J. C. Barnard, and Y. Luo (2006), Remote sensing of cloud properties using ground-based measurements of zenith radiance, J. Geophys. Res., 111, D16201, doi:10.1029/2005JD006843.

Chiu, J. C., C. H. Huang, A. Marshak, I. Slutsker, D. M. Giles, B. N. Holben, Y. Knyazikhin, and W. J. Wiscombe (2010a), Cloud optical depth retrievals from the Aerosol Robotic Network (AERONET) cloud mode observations, J. Geophys. Res., 115, D14202, doi:10.1029/ 2009JD013121.

Chiu, J. C., A. Marshak, Y. Knyazikhin, and W. J. Wiscombe (2010b), Spectral invariant behavior of zenith radiance around cloud edges simulated by radiative transfer, Atmos. Chem. Phys., 10, 11,295-11,303.

Cimini, D., A. J. Gasiwski, E. R. Westwater, V. Leuski, and S. Dowlatshahi (2005), Ground-based scanning radiometer measurements during the water vapor IOP 2004: A valuable new data set for the study of the Arctic atmosphere, Proc. of 15 th ARM meeting.

Dong, X., P. Minnis, T. P. Ackerman, E. E. Clothiaux, G. G. Mace, C. N. Long, and J. C. Liljegren (2000), A 25-month database of stratus cloud properties generated from ground-based measurements at the ARM SGP site, J. Geophys. Res., 105, 4529-4538.

Dong, X., P. Minnis, and B. Xi (2005), A climatology of midlatitude continental clouds from the ARM SGP Central Facility: Part I: Low-level cloud macrophysical, microphysical, and radiative properties, J. Climate, 18, 1391-1410.

Dong, X., P. Minnis, B. Xi, S. Sun-Mack, and Y. Chen (2008), Comparison of CERES-MODIS stratus cloud properties with ground-based measurements at the DOE ARM Southern Great Plains site, J. Geophys. Res., 113, D03204, doi:10.1029/2007JD008438.

Fan, J., L. R. Leung, Z. Li, H. Morrison, H. Chen, Y. Zhou, Y. Qian, and Y. Wang (2012), Aerosol impacts on clouds and precipitation in eastern China: Results from bin and bulk microphysics, J. Geophys. Res., 117, D00K36, doi:10.1029/2011JD016537.

Forster, P., et al. (2007), Changes in atmospheric constituents and in radiative forcing, in Climate Change 2007: The Physical Science Basis. Contribution of Working Group I to the Fourth Assessment Report of the Intergovernmental Panel on Climate Change, edited by S. Solomon et al., pp. 275-277, Cambridge Univ. Press, Cambridge, U.K.

Gaffard, C., J. Nash, E. Walker, T. J. Hewison, J. Jones, and E. G. Norton (2008), High time resolution boundary layer description using combined remote sensing instruments, Ann. Geophys., 26, 2597-2612.

Han, Y., and E. Westwater (2000), Analysis and improvement of tipping calibration for ground-based microwave radiometers, IEEE Trans. Geosci. Remote Sens., 38, 1260-1276.

Harrison, L., and J. Michalsky (1994), Objective algorithms for the retrieval of optical depths from ground-based measurements, Appl. Opt., 33, 5126-5132, doi:10.1364/AO.33.005126.

Hartmann, D. L. (1993), Radiative effect of clouds on climate, in AerosolCloud-Climate Interactions, edited by P. V. Hobbs, pp. 151-170, Academic Press, San Diego, California, US.

Holben, B. N., Y. J. Kaufman, and T. F. Eck (1998), AERONET-A federated instrument network and data archive for aerosol characterization, Remote Sens. Environ., 66, 1-16.

Horváth, Á., and R. Davies (2007), Comparison of microwave and optical cloud water path estimates from TMI, MODIS, and MISR, J. Geophys. Res., 112, D01202, doi:10.1029/2006JD007101.

Houghton, J. T., Y. Ding, D. J. Griggs, M. Noguer, P. J. Van der Linden, X. Dai, K. Maskell, and C. A. Johnson (Eds) (2001), Climate Change 2001 : The Scientific Basis, 881 pp., Cambridge Univ. Press, Cambridge, U K.

King, M. D., S. Platnick, P. Yang, G. T. Arnold, M. A. Gray, J. C. Riedi, S. A. Ackerman, and K. N. Liou (2004), Remote sensing of liquid water and ice cloud optical thickness and effective radius in the Arctic: Application of airborne multispectral MAS data, J. Atmos. Oceanic Tech., 21, 857-875.

Lebsock, M. D., G. L. Stephens, and C. Kummerow (2008), Multisensor satellite observations of aerosol effects on warm clouds, J. Geophys. Res., 113, D15205, doi:10.1029/2008JD009876. 


\section{LIU ET AL.: CLOUD PROPERTIES IN EASTERN CHINA}

Lee, K. H., Z. Li, M. C. Cribb, J. Liu, L. Wang, Y. Zheng, X. Xia, H. Chen, and B. Li (2010), Aerosol optical depth measurements in eastern China and a new calibration method, J. Geophys. Res., 115, D00K11, doi:10.1029/2009JD012812.

Leontieva, E., and K. Stamnes (1996), Remote sensing of cloud optical properties from ground-based measurements of transmittance: A feasibility case, J. Appl. Meteorol., 35, 2012-2022.

Leontieva, E., K. Stammes, and J. A. Olseth (1994), Cloud optical properties at Bergen (Norway) based on the analysis of long-term solar irradiance record, Theor. Appl. Climatol., 50, 73-82.

Li, Z., A. P. Trishchenko, H. W. Barker, G. L. Stephens, and P. Partain (1999), Analyses of Atmospheric Radiation Measurement (ARM) program's Enhanced Shortwave Experiment (ARESE) multiple data sets for studying cloud absorption, J. Geophys. Res., 104, 19,127-19,134.

Li, Z., et al. (2007), Preface to special section on East Asian Studies of Tropospheric Aerosols: An International Regional Experiment (EASTAIRE), J. Geophys. Res., 112, D22S00, doi:10.1029/2007JD008853.

Li, Z., et al. (2011), East Asian Studies of Tropospheric Aerosols and their Impact on Regional Climate (EAST-AIRC): An overview, J. Geophys. Res., 116, D00K34, doi:10.1029/2010JD015257.

Liljegren J. C., and B. M. Lesht (2004), Preliminary results with the twelvechannel microwave radiometer profiler at the North Slope of Alaska Climate Research Facility, Fourteenth ARM Science Team Meeting Proceedings, Albuquerque, New Mexico.

Liljegren, J. C., E. E. Clothiaux, G. G. Mace, S. Kato, and X. Dong (2001), A new retrieval for cloud liquid water path using a ground-based microwave radiometer and measurements of cloud temperature, J. Geophys. Res., 106, 14,485-14,500.

Liu, J., Y. Zheng, Z. Li, C. Flynn, and M. Cribb (2012), Seasonal variations of aerosol optical properties, vertical distribution and associated radiative effects in the Yangtze Delta region of China, J. Geophys. Res., 117, D00K38, doi:10.1029/2011JD016490.

Maddux, B. C., S. A. Ackerman, and S. Platnick (2010), Viewing geometry dependencies in MODIS cloud products, J. Atmos. Oceanic Tech., 27(9), 1519-1528.

Marshak, A., Y. Knyazikhin, A. B. Davis, W. J. Wiscombe, and P. Pilewskie (2000), Cloud-vegetation interaction: Use of normalized difference cloud index for estimation of cloud optical thickness, Geophys. Res. Lett., 27(12), 1695-1698, doi:10.1029/1999GL010993.

Marshak, A., Y. Knyazikhin, K. D. Evans, and W. J. Wiscombe (2004), The "RED versus NIR" plane to retrieve broken-cloud optical depth from ground-based measurements, J. Atmos. Sci., 61, 1911-1925.

Marshak, A., G. Wen, J. A. Coakley, L. A. Remer, N. G. Loeb, and R. F. Cahalan (2008), A simple model for the cloud adjacency effect and the apparent bluing of aerosols near clouds, J. Geophys. Res., 113, D14S17, doi:10.1029/2007JD009196.

McBride, P. J., K. S. Schmidt, P. Pilewskie, A. S. Kittelman, and D. E. Wolfe (2011), A spectral method for retrieving cloud optical thickness and effective radius from surface-based transmittance measurements, Atmos. Chem. Phys., 11, 7235-7252, doi:10.5194/acp-117235-2011.

McComiskey, A., G. Feingold, A. S. Frisch, D. D. Turner, M. A. Miller, LJ. C. Chiu, Q. Min, and J. A. Ogren (2009), An assessment of aerosol-cloud interactions in marine stratus clouds based on surface remote sensing, J. Geophys. Res., 114, D09203, doi:10.1029/2008JD011006.
Min, Q., and L. C. Harrison (1996), Cloud properties derived from surface MFRSR measurements and comparison with GOES results at the ARM SGP site, Geophys. Res. Lett., 23, 1641-1644.

Min, Q., E. Joseph, and M. Duan (2004), Retrievals of thin cloud optical depth from a multifilter rotating shadowband radiometer, J. Geophys. Res., 109, D02201, doi:10.1029/2003JD003964.

Pincus, R., S. Platnick, S. A. Ackerman, R. S. Hemler, and R. J. P. Hofmann (2012), Reconciling simulated and observed views of clouds: MODIS, ISCCP, and the limits of instrument simulators, J. Climate, 25, 4699-4720.

Profiler Operator's Manual (2006), Radiometrics Corporation, 2840 Wilderness Place, Boulder, C.O.

Ramanathan, V., R. D. Cess, E. F. Harrison, P. Minnis, B. R. Barkstrom, E. Ahmad, and D. L. Hartmann (1989), Cloud-radiative forcing and climate: Results from the Earth Radiation Budget Experiment, Science, 243, 57-63.

Rossow, W. B., and L. C. Garder (1993), Cloud detection using satellite measurements of infrared and visible radiances for ISCCP, J. Climate, 6, 2341-2369.

Schaaf, C. B., et al. (2002), First operational BRDF, albedo nadir reflectance products from MODIS, Remote Sens. Environ., 83(1-2), 135-148.

Stamnes, K., S. C. Tsay, W. J. Wiscombe, and K. Jayaweera (1988), Numerically stable algorithm for discrete-ordinate-method radiative transfer in multiple scattering and emitting layered media, Appl. Opt., 27, 2502-2512.

Stephens, G. L., and J. M. Haynes (2007), Near global observations of the warm rain coalescence process, Geophys. Res. Lett., 34, L20805, doi:10.1029/2007GL030259.

Stephens, G. L., and C. Kummerow (2007), The remote sensing of clouds and precipitation from space: A review, J. Atmos. Sci., 64, 3742-3765.

Suzuki, K., T. Y. Nakajima, and G. L. Stephens (2010), Particle growth and drop collection efficiency of warm clouds as inferred from joint CloudSat and MODIS observations, J. Atmos. Sci., 67(9), 3019-3032.

Turner, D. D., et al. (2007), Thin liquid water clouds: Their importance and our challenge, Bull. Am. Meteorol. Soc., 88, 177-190.

Várnai, T., and A. Marshak (2002), Observations of three-dimensional radiative effects that influence MODIS cloud optical thickness retrievals, J. Atmos. Sci., 59(9), 1607-1618.

Wang, T., and Q. Min (2008), Retrieving optical depths of optically thin and mixed-phase clouds from MFRSR measurements, J. Geophys. Res., 113 D19203, doi:10.1029/2008JD009958.

Ware, R., R. Carpenter, J. Güldner, J. Liljegren, T. Nehrkorn, F. Solheim, and F. Vandenberghe (2003), A multichannel radiometric profiler of temperature, humidity, and cloud liquid, Radio Sci., 38(4), 8079, doi:10.1029/ 2002RS002856.

Wood, R., T. L. Kubar, and D. L. Hartmann (2009), Understanding the importance of microphysics and macrophysics for warm rain in marine low clouds. Part II: Heuristic models of rain formation, J. Atmos. Sci., 66, 2973-2990

Yang, Y., A. Marshak, J. Chiu, W. J. Wiscombe, S. P. Palm, A. B. Davis, D. A. Spangenberg, L. Nguyen, J. D. Spinhirne, and P. Minnis (2008) Retrievals of thick cloud optical depth from the Geoscience Laser Altimeter System (GLAS) by calibration of solar background signal J. Atmos. Sci., 65(11), 3513-3526.

Zhang, M. H., et al. (2005), Comparing clouds and their seasonal variations in 10 atmospheric general circulation models with satellite measurements, J. Geophys. Res., 110, D15S02, doi:10.1029/2004JD005021. 